\title{
A lesson learnt: the rise and fall of Lariam and Halfan
}

Ashley M Croft

J R Soc Med 2007; 100:170-174

\section{INTRODUCTION}

Lariam (pharmacological name mefloquine) is an antimalaria drug discovered by the US Army shortly after the Vietnam War, and subsequently marketed worldwide by $\mathrm{F}$. Hoffmann-La Roche. The first reported trials of mefloquine were in prisoners, and were performed at the Joliet Correctional Center, Illinois, in 1975, and at the Maryland House of Correction in 1976. ${ }^{1,2}$

Halfan (pharmacological name halofantrine) is an antimalaria drug chemically related to mefloquine and quinine. Like Lariam, Halfan emerged from the US Army's huge post-Vietnam antimalaria drug discovery programme. ${ }^{3}$ Halfan was first described in the literature in November 1982. ${ }^{4}$ During the 1980s and 1990s, Halfan was marketed by Smith Kline Beecham.

There is no question that safe and effective antimalaria drugs were needed in the second half of the twentieth century, once it became apparent that the Plasmodium had developed resistance to the mainstay of antimalaria therapy, namely chloroquine. Chloroquine resistance was observed first in Thailand in 1957, then on the ColombianVenezuelan border in 1959, and in Kenya and Tanzania in 1978. ${ }^{5}$ Within a decade of Lariam and Halfan being marketed, however, the safety of both these novel agents was in doubt.

This essay looks at the unusual developmental history of Lariam and Halfan, explains the circumstances under which both drugs rose in esteem with policy makers and prescribers and then fell into disfavour with consumers, and summarizes the lessons learnt in the process. These lessons need to be recorded and acted upon, to prevent a repetition of the same mistakes with the next generation of antimalaria compounds.

\section{BACKGROUND}

Both Lariam and Halfan were discovered at the Experimental Therapeutics Division of the Walter Reed Army Institute of Research (WRAIR) in Washington DC. ${ }^{3}$ In the earliest published reports, these two drugs had not yet been

Medical Branch, Headquarters 5th Division, Copthorne Barracks, Shrewsbury SY3 8LZ, UK

Correspondence to: Lieutenant Colonel A M Croft RAMC

E-mail: ashley.croft810@land.mod.uk named, and they were still referred to by their respective Walter Reed experimental numbers: WR 142490 and WR $171669 .{ }^{1,4}$ Lariam and Halfan were the two main progeny of the WRAIR malaria drug discovery programme, which ran from 1963 until 1976.

Over a 15 -year period, vast resources were voted by the US federal government to fund WRAIR's antimalaria drug research, which at the time was the largest drug discovery programme ever mounted. The political driving force behind the programme was the severe clinical setback experienced by the US military during the Vietnam War, when at one stage $1 \%$ of US combat troops were succumbing to malaria each day. ${ }^{6}$ Because of the size and urgency of the research task, WRAIR collaborated with numerous governmental, academic and commercial organizations, including 175 external contractors. ${ }^{7}$

From the early 1960s onwards, WRAIR screened over 250000 potential antimalaria compounds. ${ }^{8}$ Lariam was number 142490 in this long series, and Halfan was number 171669 . Because the US military was and remains forbidden by Congress from operating in the commercial sector, WRAIR engaged the holding companies F. Hoffmann-La Roche and Smith Kline Beecham to market these two promising novel agents.

The precise details of the three-way business agreement between WRAIR, the US federal government and the two multinational drug companies which marketed Lariam and Halfan have not been made public. It appears, however, that all of WRAIR's phase I and phase II clinical trial data on Lariam and Halfan were delivered as a free good to F. Hoffmann-La Roche and to Smith Kline Beecham. Drug approval was swiftly granted by the Food and Drug Administration (FDA): Lariam was approved in 1989 and Halfan in 1992.

From the perspective of the two drug companies chosen to act as the marketing arm of WRAIR, the primary commercial potential of Lariam and Halfan lay in their ability to prevent malaria in tourists and business travellers to the tropics. Prior to their obtaining FDA approval, however, no randomized Phase III tolerability study was carried out on either drug in a normal study population of healthy civilian volunteers. ${ }^{9}$ Likewise, there was no serious attempt prior to licensing to explore the potential drugdrug interactions of either Lariam and Halfan; some of the fatal drug reactions which followed may have been a direct 
consequence of the resulting gap in the prescribers' knowledge base.

Within months of their being licensed, major safety concerns around Lariam and Halfan began to emerge. These two compounds should have been welcomed by the public as being safe, effective and lifesaving pharmaceutical weapons in a world where international travel was increasing exponentially and where chloroquine-resistant malaria seemed to be spreading just as rapidly. ${ }^{10}$ Instead, consumers viewed the two new drugs with disquiet, and later with concern and alarm.

\section{THE SITUATION TODAY}

Though still prescribed in most countries, both for preventing and treating malaria, Lariam is now known to cause neurotoxicity. ${ }^{11}$ This unexpected property came to prominence in the mid-1990s, when national pharmacovigilance centres, initially in Europe, began to receive recurring reports of neuropsychiatric adverse effects caused by this new antimalaria agent. In the Netherlands during 1998 and 1999, mefloquine was respectively the most and the second most cited drug in spontaneous reports of drugrelated illness made to the Lareb Pharmacovigilance Foundation. ${ }^{12}$ Around the same time, it was reported that $60 \%$ of all the mefloquine occurrences notified to the WHO's Uppsala Monitoring Centre cited neuropsychiatric disturbance secondary to the drug. ${ }^{12}$
Belatedly, three randomized controlled trials were carried out in healthy volunteer populations, and were reported between 2001-2003. ${ }^{13-15}$ The studies confirmed mefloquine's potential for causing psychological illness, and all three study reports described an excess of neuropsychiatric adverse effects in the mefloquine arm. ${ }^{13-15}$ Around the same time an analysis of the cause of illness in 4524 travellers returning from sub-Saharan Africa to the northern hemisphere found that, excluding diarrhoea and fever as causes, mefloquine was the fifteenth most common cause of post-travel illness. ${ }^{16} \mathrm{~A}$ case control study of 564 Dutch travellers between 1997 to 2000 found a threefold increase in the incidence of psychiatric events with mefloquine use (OR 3.5, 95\% CI 1.4-8.7), and a very high risk of psychiatric events in women users of the drug (OR 47.1, 95\% CI 3.8-578.6). ${ }^{17} \mathrm{~A}$ survey of the recent literature shows that mefloquine has been causally associated with 19 deaths in users, including three suicides (Table 1). ${ }^{18-26}$

By 2004, public concern in the US was such that the FDA took the exceptional step of insisting that a patient medication guide be given to all recipients of mefloquine prescriptions. ${ }^{27,28}$ The FDA thus followed the example of the Committee on Safety of Medicines, which had advised British doctors in 1996 to warn patients about the incidence of neuropsychiatric adverse effects with mefloquine. As was pointed out in the British Medical Journal, this advice overturned accepted clinical practice in the UK, which at that time was to warn patients about common adverse effects only. ${ }^{29,30}$

Table 1 Nineteen deaths causally associated with Lariam (mefloquine) use

\begin{tabular}{|c|c|c|c|}
\hline Reference & $\begin{array}{l}\text { Patient } \\
\text { nationality }\end{array}$ & Patient age & Clinical details \\
\hline 18 & American (USA) & Not stated & After one mefloquine tablet, patient experienced cardiopulmonary arrest, death. \\
\hline 19 & Thai & 13 & $\begin{array}{l}\text { Malaria recrudesced } 21 \text { days after mefloquine treatment. Given halofantrine over } \\
3 \text { days. Experienced sudden cardiac arrest, death. }\end{array}$ \\
\hline 20 & British & 6 & $\begin{array}{l}\text { Developed blistering of lips and oral mucosae. Generalized erythema and } \\
\text { blistering, then exfoliation of the mucosae. Ulceration of the mucosae, hair and } \\
\text { nail loss. Cardiac asystole, death. }\end{array}$ \\
\hline 21 & British & 37 & $\begin{array}{l}\text { After taking Lariam for overseas trip, became acutely depressed. Committed } \\
\text { suicide by jumping to his death from the roof of a mansion block. }\end{array}$ \\
\hline 22 & German & 33 & $\begin{array}{l}\text { Took two Lariam tablets for suspected malaria. After } 4 \text { hours, experienced } \\
\text { headaches, 'burning in bones', deafness, dizziness. Confused, panic, } \\
\text { depression. Hospitalized. Committed suicide. }\end{array}$ \\
\hline 23 & American (USA) & 22 & $\begin{array}{l}\text { Early during mefloquine prophylaxis, experienced fever (102 degrees), chills, } \\
\text { headache, cough. Initially treated as malaria. Then, during a 2-hour car ride, } \\
\text { experienced a 'head rush.' Collapsed, died. }\end{array}$ \\
\hline 24 & British & Not stated & $\begin{array}{l}\text { Eight fatal reactions to mefloquine, reported to the UK Medicines Control } \\
\text { Agency. }\end{array}$ \\
\hline 25 & Not stated & Not stated & $\begin{array}{l}\text { Four fatal reactions to Lariam, recorded on the manufacturer's database of } \\
\text { adverse drug reactions. }\end{array}$ \\
\hline 26 & French & 27 & $\begin{array}{l}\text { Treated with Lariam for } 48 \text { hours. Committed suicide } 6 \text { weeks later, through self- } \\
\text { inflicted multiple knife wounds. }\end{array}$ \\
\hline
\end{tabular}


Also unexpectedly, Halfan was found after licensing to cause ventricular dysrhythmias that were often fatal. $23,31-33$ This unforeseen property of the drug (unforeseen because unresearched) came to light serendipitously, in a prospective electrocardiographic study of Karen patients that was reported in the Lancet in $1993 .{ }^{34}$ Halfan is no longer recommended by WHO for the self-treatment of malaria, and the drug is not listed for this indication in the British National Formulary or in other national pharmacopoeias. Halfan is not now approved in any country for malaria prophylaxis. ${ }^{35}$ The 2006 edition of Goodman and Gilman states that:

'Because halofantrine displays erratic bioavailability, potentially lethal cardiotoxicity, and extensive cross-resistance with mefloquine, its use generally is not [now] recommended. 36

The disappointing performance in clinical practice of these two drugs, developed at enormous cost to the US taxpayer, could not have been anticipated 30 years ago. Or could it?

\section{WHAT WENT WRONG?}

Both Lariam and Halfan are products of what has been called 'the military-industrial complex'. This is an overused term, but one that describes a real entity.

The partnership between industry and the military has achieved some astonishing technical feats-witness the placing of a man on the moon. In the area of patient care, however, the health and wellbeing of consumers of health care is protected by regulations which, however imperfect and seemingly cumbersome, are derived from decades of use and experience. These regulations reach forward in time, protecting future cohorts of patients from prescriberinduced harm, but also slowing up pharmaceutical innovations which in some cases may be needed urgently. Powerful lobbies, impatient of delay (and acting in what they may see as the public's best interests) may be tempted to disregard those regulations. The clinical consequences of doing so may be unforeseen, however.

As stated above, the underpinning safety and pharmacokinetic studies which should have been performed prior to the licensing of Lariam and Halfan, on the main intended target group for both drugs (namely, tourists and business travellers), were never carried out. ${ }^{9}$

In the case of Lariam, the first randomized controlled trial of the drug in a mixed population of general travellers was not reported until 2001.13 Of the study participants randomized to receive mefloquine, $67.1 \%$ reported $\geqslant 1$ adverse event, and in $6 \%$ of mefloquine users these events were severe (defined as requiring medical advice). Had this licensing, as it should have been, it is certain that the FDA and the other national licensing authorities which approved Lariam for use prophylactically, in and around 1989, would not at the time have endorsed this drug. ${ }^{37}$

It seems probable that in the late 1980s and early 1990s the FDA and other national licensing bodies were influenced, perhaps subliminally, by the powerful military-industrial-governmental lobby into over-hasty decisions to approve the marketing of both Lariam and Halfan. These two drugs were authorized for public use on the basis of an incomplete knowledge base, and at too early a stage in the normal cycle of drug development.

Post-marketing surveillance of Lariam and Halfan took the place of normal, responsible, pre-licensing research into the safety of these two agents.

Travel medicine experts in most countries were slow to recognize the danger signals associated with Lariam and Halfan, and for many years the public's concern about Lariam, in particular, was dismissed as 'media hype'. A senior WRAIR scientist, writing in 2001, deplored what he called ' . . . the "herd mentality" of mefloquine associated psychoses', and stated defiantly that 'mefloquine (Lariam ${ }^{\circledR}$ ) remains the prophylaxis of choice for US soldiers and travellers. ${ }^{38}$ As late as 2005 a reviewer in the New England Journal of Medicine, also an employee of the US military for over 20 years, continued to maintain, in the face of compelling empirical and experimental evidence to the contrary, that Lariam was a 'well tolerated' drug. ${ }^{39}$ However, by the following year a US military research team, based partly at WRAIR, conceded that:

'Walter Reed Army Institute of Research is currently investigating mefloquine analogues, seeking one with similar efficacy but reduced neuropsychiatric toxicity. ${ }^{3}$

The victims of this pharmacological muddle have been those many business travellers, embassy staff, tourists, aid workers, missionaries, soldiers and others who were well at the start of their journeys into malaria-endemic areas, were prescribed Lariam or Halfan by their physicians, and who then suffered unforeseen (because unresearched) harms from their chemoprophylaxis.

Effectively, all users of Lariam and Halfan, from the point of licensing onwards, have been involved in a natural experiment to determine the true safety margin, at current dosages, of these two poorly understood antimalaria drugs. Consumers have been unwitting recruits to this longitudinal study, rather than informed partners. ${ }^{9}, 40$ The rapid public rejection of Lariam and Halfan could have been anticipated, since users of malaria chemoprophylaxis differ from normal patients in that they are by definition healthy people, and on this account they are unwilling to accept even relatively minor drug-related harms. ${ }^{41}$

Ironically, for a drug that was discovered by the military, soldiers have been amongst the most vocal critics 
of Lariam. Following a Parliamentary enquiry, Canada's auditor general condemned protocol abuses in which 900 Canadian soldiers deploying to Somalia were prescribed Lariam in 1992-1993, at a time when the drug was still unlicensed in Canada. ${ }^{42}$ In the Netherlands, reports of severe adverse drug reactions in soldiers who had used Lariam prophylaxis while undertaking peacekeeping duties in Cambodia prompted questions in Parliament and intense public debate. ${ }^{43}$ In the US, military epidemiologists have investigated the possible role of Lariam in a series of murders and suicides among soldiers in North Carolina who had served in Afghanistan. ${ }^{44}$ Most recently, the Australian military has been threatened with legal action by soldiers reporting severe and disabling symptoms which they attributed to Lariam prophylaxis. ${ }^{45}$

\section{THE FUTURE}

Sir Iain Chalmers has pointed out how the biased underreporting of research harms and sometimes kills patients. ${ }^{46}$ The under-reporting of research, he states, is essentially a form of misconduct, since it can lead to seriously misleading recommendations for clinical practice and for new research. 47

The case of Lariam and Halfan does not exactly fit the model of scientific irresponsibility which has been highlighted by Chalmers and others. It is not the case, with these two antimalaria agents, that inconvenient research data on their adverse effects was deliberately withheld from national drug licensing authorities, and from the public. The necessary pre-licensing research was simply never carried out.

The prime lesson from the Lariam and Halfan experience is that drugs intended primarily for use by healthy people must be genuinely well tolerated, and indeed they must demonstrate much better tolerability under their actual conditions of use than would normally be required for, say, antimitotic agents. Future research studies of malaria chemoprophylaxis must address the unanswered questions and outstanding gaps in the evidence. ${ }^{48}$ In particular, planned research studies must be carried out on the population of interest (that is, on tourists and business travellers) and not on a convenience sample of prisoners, or soldiers. ${ }^{49}$

Despite the public outcry about Lariam and Halfan, it is extraordinary that no real attempt has yet been made to properly explore the adverse effects of these two drugs in terms of what causes these effects, who is likely to experience them, how long the effects typically last, how the effects can be mitigated, and how they should be managed if they do occur.

There are several plausible mechanisms through which the unwanted effects of Lariam and Halfan, which are structurally related quinoline derivatives, might be mediated. Croft and Herxheimer suggested in 2002 that many of the adverse effects of mefloquine may be a posthepatic syndrome caused by primary liver damage, with a subset of mefloquine users also experiencing thyroid disturbance. ${ }^{50}$ More recently, Aarnoudse and colleagues have hypothesized that the neuropsychiatric effects of mefloquine are associated with polymorphisms in the MDR1/ABCB1 gene that encodes for the efflux pump P-glycoprotein. ${ }^{51}$ Both theories remain speculative, however, since the rigorous studies needed to test the respective hypotheses have not yet been carried out.

Because the harms of mefloquine have never been adequately investigated, and because there appears to be no incentive for the manufacturer of Lariam ever to do this, it is likely that mefloquine, which like halofantrine is a potentially important weapon in the limited pharmaceutical arsenal against malaria, will be discarded along with its sister drug. A recent British review of the treatment options for malaria does not mention mefloquine at all. ${ }^{52}$ This apparent willingness to casually sideline two undoubtedly lifesaving drugs represents a waste of resources, and a loss also to future travellers and patients. Researchers, policy makers and prescribers must learn from this experience or be condemned to repeat it. Many of the individual medical tragedies detailed in the table need never have occurred. Powerful institutional pressures must never again override the needs and rights of patients. ${ }^{46,47}$

\section{Competing interests None declared.}

Acknowledgments This essay was the Prize Winner in the RSM Section of Pharmaceutical Medicine \& Research Prize Essay Competition 2006. I am grateful to the sponsors of the Prize and to all those fellow scientists who helped me develop the ideas outlined in this essay. The opinions expressed here are my own.

\section{REFERENCES}

1 Trenholme GN, Williams RL, Desjardins RE, et al. Mefloquine (WR $142,490)$ in the treatment of human malaria. Science 1975;190:792-4

2 Clyde DF, McCarthy VC, Miller RM, Hornick RB. Suppressive activity of mefloquine in sporozoite-induced human malaria. Antimicrobial Agents Chemother 1976;9:384-6

3 Kitchen LW, Vaughn DW, Skillman DR. Role of US military research programs in the development of US Food and Drug Administrationapproved antimalarial drugs. Clin Infect Dis 2006;43:67-71

4 Cosgriff TM, Boudreau EF, Pamplin CL, Doberstyn EB, Desjardins RE, Canfield CJ. Evaluation of the antimalarial activity of the phenanthrenemethanol halofantrine (WR 171,669). Am J Trop Med Hyg 1982;31:1075-9

5 Croft AM, Geary K. Chloroquine and its combinations. In: Schlagenhauf P, ed. Travellers' Malaria. Hamilton, Ontario: Decker, 2001

6 Bruce-Chwatt LJ. John Hull Grundy lecture. Mosquitoes, malaria and war; then and now. J R Army Med Corps 1985;131:85-99 
7 Tigertt WD. The Army malaria research program. Ann Intern Med 1969; 70: 150-3

8 Croft AM, Whitehouse DP, Cook GC, Beer MD. Safety evaluation of the drugs available to prevent malaria. Expert Opin Drug Saf 2002; 1: 19-27

9 Croft AM, Garner P, Squire SB. Malaria prevention for travelers. JAMA 1998; 279: 990

10 Magill AJ. Malaria: epidemiology and risk to the traveler. In: Keystone JS, Kozarsky PE, Freedman DO, Nothdurft HD, Connor BA, eds. Travel medicine. New York: Mosby, 2004: 131-6

11 Dow G, Bauman R, Caridha D, et al. Mefloquine-induces dose-related neurological effects in a rat model. Antimicrob Agents Chemother 2006; 50: $1045-53$

12 Heeringa $M$, van Grootheest AC. Profylactisch gebruik van mefloquine-bijwerking geen reden tot verandering van indicatie. Pharmaceutisch Weekblad 2000; 135: 788-792

13 Overbosch D, Schilthuis H, Bienzle U, et al. Atovaquone-proguanil versus mefloquine for malaria prophylaxis in nonimmune travelers: results from a randomized double-blind study. Clin Infect Dis 2001;33:1015-21

14 Potasman I, Juven Y, Weller B, Schwartz E. Does mefloquine prophylaxis affect electroencephalographic patterns? Am J Med 2002; 112: $147-9$

15 Schlagenhauf P, Tschopp A, Johnson R, et al. Tolerability of malaria chemoprophylaxis in non-immune travellers to sub-Saharan Africa: multicentre, randomised, double blind, four arm study. BMJ 2003; 327: $1078-81$

16 Freedman DO, Weld LH, Kozarsky PE, et al. Spectrum of disease and relation to place of exposure among ill returned travelers. $N$ Engl J Med 2006; 354: 119-30

17 Van Riemsdijk MM, Sturkenboom MC, Pepplinkhuizen L, Stricker $\mathrm{BH}$. Mefloquine increases the risk of serious psychiatric events during travel abroad: a nationwide case-control study in the Netherlands. J Clin Psychiatry 2005; 66: 199-204

18 Anonymous. Mefloquine for malaria. Medical Letter on Drugs and Therapeutics 1990; 31: 13-4

19 Nosten F, ter Kuile FO, Luxemburger C, et al. Cardiac effects of antimalarial treatment with halofantrine. Lancet 1993; 341: 1054-6

20 McBride SR, Lawrence CM, Pape SA, Reid CA. Fatal toxic epidermal necrolysis associated with mefloquine antimalarial prophylaxis. Lancet 1997; 349: 101

21 News report. Roche's Lariam linked to a suicide in UK. Scrip 1998; 2331: 23

22 Anonymous. Netwerk aktuell — Suizid nach zwei Tabletten Mefloquin (LARIAM). Arznei-telegramm 2000; 31: 23

23 Centers for Disease Control and Prevention. Sudden death in a traveler following halofantrine administration-Togo, 2000. Morb Mortal Wkly Rep 2001; 50: 169-70

24 Smith HR, Croft AM, Black MM. Dermatological adverse effects with the antimalarial drug, mefloquine: a review of 74 published case reports. Clin Exp Derm 1999; 24: 249-54

25 Nosten F, van Vugt M. Neuropsychiatric adverse effects of mefloquine. What do we know and what should we do? CNS Drugs 1999; 11: 1-8

26 Jousset N, Guilleux M, de Gentile L, Le Bouil A, Turcant A, RougéMaillart C. Suicide spectaculaire lié à une prise de méfloquine. Presse Med 2006; 35: 789-92

27 News report. FDA requires warnings on anti-malaria drug Lariam. Consum Rep 2004; 69: 45

28 Medication guide: Lariam [online]. Available at http://www.fda.gov/ medwatch/SAFETY/2003/LariamMedGuide.pdf (Accessed 02/11/ 2006)
29 Committee on Safety of Medicines. Mefloquine (Lariam) and neuropsychiatric reactions. Current Problems in Pharmacovigilance 1996; 2: 6

30 Warner J. Advice to warn patients about rare side effects overturns accepted practice. BMJ 1996; 313: 1554

31 Akhtar T, Imran M. Sudden deaths while on halofantrine treatmentsa report of two cases from Peshawar. J Pak Med Assoc 1994; 44: 120-1

32 Malvy D, Receveur MC, Ozon P, et al. Fatal cardiac incident after use of halofantrine. J Travel Med 2000; 7: 215-6

33 Bouchaud O, Bruneel F, Schiemann R, Peytavin G, Coulaud JP. Severe cardiac toxicity due to halofantrine: importance of underlying heart disease. J Travel Med 2002; 9: 214-5

34 Nosten F, ter Kuile FO, Luxemburger C, et al. Cardiac effects of antimalarial treatment with halofantrine. Lancet 1993; 341: 1054-6

35 Shanks GD, Edstein MD. Modern malaria chemoprophylaxis. Drugs 2005; 65: 2091-110

36 Shapiro TA, Goldberg DE. Chemotherapy of protozoal infections: malaria. In: Brunton LL, Lazo JS, Parker KL, eds. Goodman and Gilman's The Pharmacological Basis of Therapeutics. $11^{\text {th }}$ edition. New York: McGraw-Hill, 2006: 1021-47

37 Croft AM, Beer MD, Herxheimer A. Effectiveness of antimalarial drugs. N Engl J Med 2005; 353: 420-2

38 W Milhous. Development of new drugs for chemoprophylaxis of malaria. Bull Soc Pathol Exot 2001; 24: 149-51

39 Baird JK. Effectiveness of antimalarial drugs. N Engl J Med 2005; 352: 1565-77

40 Burke BM. Mefloquine. Lancet 1993; 341: 1605-6

41 Croft AM, Garner P. Mefloquine for preventing malaria in nonimmune adult travellers. The Cochrane Database of Systematic Reviews 2000, Issue 4. Art. No.: CD000138. DOI: 10.1002/ 14651858.CD000138

42 News report. Canadian soldiers used as 'guinea pigs'? Can Med Assoc J 1999; 160: 1814

43 van Puijenbroek EP, Bouvy M. Mefloquine (Lariam) in het nieuws. Pharmaceutisch Weekblad 1995; 130: 912

44 News report. Lariam suicide warning. BMJ 2002; 325: 510

45 Burton B. Australian army faces legal action over mefloquine. BMJ 2004; 329: 1062

46 Chalmers I. From optimism to disillusion about commitment to transparency in the medico-industrial complex. J R Soc Med 2006; 99 : $337-41$

47 Chalmers I. Under-reporting research is scientific misconduct. JAMA 1990; 263: 1405-8

48 Brown $\mathrm{P}$, Brunnhuber $\mathrm{K}$, Chalkidou K, et al. How to formulate research recommendations. BMJ 2006; 333: 804-6

49 Richardson WS, Wilson MC, Nishikawa J, Hayward RSA. The wellbuilt clinical question: a key to evidence-based decisions. ACPJ Club 1995; 123: A12-A13

50 Croft AM, Herxheimer A. Adverse effects of the antimalaria drug, mefloquine: due to primary liver damage with secondary thyroid involvement? BMC Public Health 2002; 25: 6. Available at http:// www.biomedcentral.com/my/ access.asp?man_id=9039985831098605 (Accessed 02/11/2006)

51 Aarnoudse AL, van Schaik RH, Dieleman J, et al. MDR1 gene polymorphisms are associated with neuropsychiatric adverse effects of mefloquine. Clin Pharmacol Ther 2006; 80: 367-74

52 Whitty CJ, Lalloo D, Ustianowski A. Malaria - an update on treatment of adults in non-endemic countries. BMJ 2006; 333: 241-5 